\title{
Inhibition and Stimulation of Nitrification by Potassium Ethyl Xanthate
}

\author{
By SUSAN E. UNDERHILL† AND J. I. PROSSER* \\ Department of Genetics and Microbiology, University of Aberdeen, Marischal College, \\ Aberdeen $A B 9$ IAS, UK
}

(Received 10 March 1987; revised 27 June 1987)

\begin{abstract}
Inhibition of autotrophic ammonia and nitrite oxidation by potassium ethyl xanthate (PEX) was studied in ammonium- and nitrite-limited chemostat cultures of Nitrosomonas europaea and Nitrobacter, respectively. Ammonia and nitrite oxidation were both stimulated by addition of low concentrations of PEX $\left(0 \cdot 1 \mu \mathrm{g} \mathrm{ml}^{-1}\right)$, which significantly decreased steady-state substrate concentrations and increased steady-state cell concentrations. Addition of similar concentrations to exponentially growing cultures resulted in a slight stimulation of growth of Nitrobacter but did not affect Nitrosomonas. Inhibition of ammonia and nitrite oxidation by higher concentrations of PEX resulted in establishment of steady states without induction of lag phases, observed in batch culture, which would have resulted in wash-out. Establishment of steady states occurred more quickly and with less variation in substrate concentrations following addition of inhibitory rather than stimulatory concentrations of PEX. Steady-state data indicate that PEX may act as a competitive inhibitor of nitrite oxidation by Nitrobacter.
\end{abstract}

\section{INTRODUCTION}

Autotrophic nitrification is the oxidation of ammonia to nitrate and occurs in two stages. Ammonium is oxidized to nitrite by autotrophic ammonia oxidizers such as Nitrosomonas, Nitrosolobus and Nitrosococcus, and nitrite is then oxidized to nitrate by the autotrophic nitrite oxidizer Nitrobacter. In regions of intensive agriculture, where ammonium-based fertilizers are applied at high levels, nitrification is an increasingly serious problem, as nitrate is readily leached from the soil. This results in economic losses due to low efficiency of fertilizer utilization and also increased nitrate pollution of run-off waters, and can only be prevented by application of nitrification inhibitors. A range of such inhibitors is available for application along with ammonium-based fertilizers, the most commonly used being nitrapyrin (Goring, 1962). Inhibition of nitrification by xanthates was first reported by Lees (1952) and their potential commercial use has been investigated recently by Ashworth et al. $(1977,1979,1980)$. These compounds release carbon disulphide which is a potent inhibitor of nitrification (Powlson \& Jenkinson, 1971) and the most suitable compound for field application is potassium ethyl xanthate (PEX), which provides a slow release of carbon disulphide in the soil over several weeks.

Underhill \& Prosser (1985) studied inhibition of nitrification by PEX in sterilized soil and in liquid batch culture inoculated with Nitrosomonas europaea and Nitrobacter sp. Soil provided protection from inhibition of both ammonia and nitrite oxidation but within each experimental system the two processes were affected to different extents. In liquid culture nitrite oxidation was more sensitive to inhibition than ammonia oxidation while ammonia oxidation was more sensitive than nitrite oxidation in soil. It was proposed that adsorption of PEX or its breakdown products to the soil surface, along with ammonium ions, was responsible for this differential

† Present address: School of Chemical Engineering, University of Bradford, Bradford, West Yorkshire BD7 1DP, UK.

Abbreviation: PEX, potassium ethyl xanthate.

0001-4064 (C) 1987 SGM 
inhibitory effect. This was supported by studies of growth on anion and cation exchange resin beads, which demonstrated that substrate adsorption was the major factor in surface colonization of nitrifying bacteria (Underhill \& Prosser, 1987).

Although batch culture systems are routinely used to study nitrification in soil and to assess the efficiency of inhibitors they do not provide information on growth at sub-maximal rates and at low substrate concentrations. Growth in the soil is likely to be substrate limited as ammonium rarely accumulates above the saturation constants for ammonia oxidation and the nitrite concentration is usually less than $1 \mu \mathrm{g} \mathrm{ml}^{-1}$. Substrate-limited growth is most conveniently studied in continuous flow systems which also allow determination of the effect of inhibition on features such as cell activity and biomass yield. Analysis of steady-state kinetics can provide information on the mechanism of inhibition and transient growth kinetics may be studied following step changes in inhibitor concentration. The majority of continuous flow studies of nitrification have used packed column reactors (Prosser \& Bazin, 1987) containing soil or glass beads, but these have not been used to investigate specific inhibitors. There are few reports of growth of pure cultures of nitrifying bacteria in stirred, homogeneous continuous flow systems, exceptions being growth of ammonia oxidizers and determination of $\mathrm{C}: \mathrm{N}$ ratios (Skinner \& Walker, 1961; Glover, 1985) and growth of both ammonia and nitrite oxidizers under steady state and transient conditions (Keen \& Prosser, 1987a). None has been used to study inhibition of ammonium or nitrite oxidation.

In this paper we describe the effect of PEX on ammonium- and nitrite-limited cultures of $N$. europaea and Nitrobacter and discuss the relevance of such work to the application of nitrification inhibitors in the soil.

\section{METHODS}

Organisms and growth media. Soil isolates of Nitrosomonas europaea and Nitrobacter sp. were kindly supplied by Dr R. M. Macdonald, Rothamsted Experimental Station, Harpenden, UK. Techniques for the maintenance of cultures and for assessment of growth and contamination by heterotrophs were described by Underhill \& Prosser (1985). The inorganic medium of Skinner \& Walker (1961) was used in all experiments. For growth of Nitrosomonas ammonium was supplied as $\left(\mathrm{NH}_{4}\right)_{2} \mathrm{SO}_{4}$ at a concentration of $50 \mu \mathrm{g} \mathrm{NH}_{4}^{+}-\mathrm{N} \mathrm{ml}^{-1}$. This was replaced by $50 \mu \mathrm{g} \mathrm{NO}_{2}^{-}-\mathrm{N} \mathrm{ml}^{-1}$ as $\mathrm{NaNO}_{2}$ for growth of Nitrobacter. Sodium carbonate solution $(5 \%, \mathrm{w} / \mathrm{v})$ was added to all media after autoclaving at $121^{\circ} \mathrm{C}$ for $20 \mathrm{~min}$, to give a final $\mathrm{pH}$ of 8.0 , and was also used to maintain this $\mathrm{pH}$ during growth of Nitrosomonas, which results in production of nitrous acid. All experiments were done at $30^{\circ} \mathrm{C}$, axenic cultures were used throughout and regular checks were made for contamination by heterotrophic organisms as described by Underhill \& Prosser (1985).

Growth in contintous culture. Continuous culture of Nitrosomonas was done in a LH Engineering Modular II Fermenter System with a 1 litre vessel and a working volume of $800 \mathrm{ml}$. A digital pH control module was used to maintain a $\mathrm{pH}$ value of 8 by automatic addition of $5 \% \mathrm{Na}_{2} \mathrm{CO}_{3}$. Nitrobacter was grown in an air-lift column fermenter with a working volume of $555 \mathrm{ml}$ described in detail by Keen \& Prosser $(1987 \mathrm{~b})$. This system is designed for the study of microbial growth on particulate surfaces but was used here to study growth of suspended cells only. Air was supplied to each system by a Hy-Flow Model C air pump (Medcalf Bros. Ltd) through a gas distribution tube, porosity 2 (Macfarlane Robson) after passage through double air filters and sterile distilled water. All bungs and connecting tubing were made of silicone rubber to prevent inhibition by carbon disulphide released from other forms of rubber (Powlson \& Jenkinson, 1971). Culture vessels were wrapped in foil to prevent photoinhibition (Bock, 1965).

Nitrosomonas or Nitrobacter were inoculated as $30 \mathrm{ml}$ volumes of a stationary phase culture and were grown in batch culture until either ammonium or nitrite was exhausted. Inorganic growth medium was then supplied by a LKB Microperpex peristaltic pump to give dilution rates of $0.033 \mathrm{~h}^{-1}$ and $0.015 \mathrm{~h}^{-1}$ for Nitrosomonas and Nitrobacter, respectively. PEX was supplied to steady-state cultures in the inflowing medium, following addition of $1 \mathrm{ml}$ of a filter-sterilized solution of xanthate to the medium reservoir to give the required concentration. Concentrations of PEX in the ranges $0-4$ and $0-10 \mu \mathrm{g} \mathrm{ml}^{-1}$ were investigated for Nitrosomonas and Nitrobacter, respectively. Wall growth of Nitrobacter became significant after approximately $1500 \mathrm{~h}$ and the effect of each PEX concentration was therefore studied separately in newly established cultures.

Evaluation of growth and steady states. Samples of effluent from each system were collected at regular intervals using a LKB 2070 Ultrorac fraction collector in test tubes containing PEX (final concentration greater than $10 \mu \mathrm{g}$ $\mathrm{ml}^{-1}$ ) to prevent further activity during storage. Samples were analysed for ammonium, nitrite or nitrate using a Technicon Autoanalyser II System. Total cell concentration was determined in samples removed directly from the culture vessel using a Thoma (Helber) counting chamber under dark-field microscopy. Establishment of a steady state was determined by analysis of substrate concentrations and total cell concentrations using Williams' 
coefficient of sequential variation (see Keen \& Prosser, 1987a). Biomass yield was determined by collecting $250 \mathrm{ml}$ of culture effluent on ice and filtering through a pre-weighed Millipore filter $(0.22 \mu \mathrm{m}$ pore size). Filters were reweighed following drying to constant weight at $100^{\circ} \mathrm{C}$ and yield coefficients are expressed as mg dry wt biomass formed $(\mathrm{mg} \mathrm{N})^{-1}$ utilized.

Batch culture experiments. The effect of addition of PEX to exponentially growing cultures of Nitrosomonas was investigated in the $\mathrm{pH}$-controlled fermenter system described above. Following inoculation of $30 \mathrm{ml}$ of a stationary phase culture of Nitrosomonas, nitrite concentration was monitored in samples of effluent until it reached $5 \mu \mathrm{g} \mathrm{NO}_{2}^{-}-\mathrm{N} \mathrm{m}^{-1}$. A filter-sterilized solution $(1 \mathrm{ml}$ ) of PEX was then added to give a final concentration of either 0.1 or $0.8 \mu \mathrm{g} \mathrm{ml}^{-1}$. Nitrite concentrations were determined in further samples and the specific rates of growth before and after addition of PEX were determined as the slopes of semi-logarithmic plots of nitrite concentration versus time. The effect of each concentration was determined in triplicate. This experiment was repeated for Nitrobacter in $250 \mathrm{ml}$ Erlenmeyer flasks containing $150 \mathrm{ml}$ inorganic medium with $100 \mu \mathrm{g} \mathrm{NO}--\mathrm{N}_{2}$ $\mathrm{ml}^{-1}$. PEX was added to give concentrations in the range $0-0.8 \mu \mathrm{g} \mathrm{m} \mathrm{m}^{-1}$ when nitrite concentration reached approximately $20 \mu \mathrm{g} \mathrm{ml}^{-1}$. Specific growth rate was determined as the slope of a semi-logarithmic plot of nitrate concentration versus time and triplicate flasks were set up for each concentration and for the control.

\section{RESULTS}

\section{Stimulation of ammonia and nitrite oxidation}

Nitrosomonas was grown in continuous culture at a dilution rate of $0.033 \mathrm{~h}^{-1}$ until establishment of steady state, assessed by measurement of ammonium concentration. The medium supply was then supplemented by $0.2 \mu \mathrm{g}$ PEX ml ${ }^{-1}$ resulting in a decrease in ammonium concentration, with a transient increase at $250 \mathrm{~h}$, to a new steady-state value after approximately $700 \mathrm{~h}$. The change in PEX concentration within the vessel $(X)$ is described by the equation: $\mathrm{d} X / \mathrm{d} t=D X_{\mathrm{r}}-D X$, where $D$ is the dilution rate and $X_{\mathrm{r}}$ represents PEX concentration in the medium reservoir. Integration of this equation yields the expression $X=X_{\mathrm{r}}-X_{\mathrm{r}} \exp ^{(-D t)}$. Rearrangement of this equation leads to an expression which allows calculation of the time taken for the concentration of xanthate within the vessel to reach $90 \%$ of that supplied. This is a function of dilution rate and equals $\ln (0 \cdot 1) /-D$. At a dilution rate of $0.033 \mathrm{~h}^{-1}$ the time taken for the concentration of PEX to reach $90 \%$ of the inflowing concentration is $150 \mathrm{~h}$. Ammonia oxidation was stimulated by $0 \cdot 2 \mu \mathrm{g} \mathrm{PEX} \mathrm{m} \mathrm{m}^{-1}$ (Fig. 1), with a decrease in steady-state ammonium concentration from 2.37 to $0.37 \mu \mathrm{g} \mathrm{NH}_{4}^{+}-\mathrm{N} \mathrm{ml}^{-1}$ and an increase in steady-state cell concentration from $1.98 \times 10^{7}$ to $3.36 \times 10^{7}$ cells ml-1 (Table 1 ). The yield coefficient for energy conversion into biomass also increased but the rate of ammonia oxidation per cell did not change significantly.

Nitrobacter was grown at a dilution rate of $0.015 \mathrm{~h}^{-1}$ and stimulation was observed at concentrations of PEX of $0 \cdot 1$ and $0 \cdot 2 \mu \mathrm{g} \mathrm{ml}^{-1}$. Fig. 2 illustrates changes in nitrite concentration from the onset of continuous flow, following initial growth in batch culture. The initial overshoot in substrate concentration, before establishment of a steady state at approximately $350 \mathrm{~h}$, was typical of initial growth of both Nitrosomonas and Nitrobacter. The nitrite concentration decreased following supplementation of medium with $0 \cdot 2 \mu \mathrm{g} \mathrm{PEX} \mathrm{ml}^{-1}$ at $400 \mathrm{~h}$. At a dilution rate of $0.015 \mathrm{~h}^{-1}$ PEX concentration will reach $90 \%$ of that supplied after $253 \mathrm{~h}$. A steady-state nitrite concentration was established approximately $250 \mathrm{~h}$ after addition of PEX. Nitrobacter cell concentration was monitored regularly and oscillated before establishment of a steady state approximately $300 \mathrm{~h}$ after addition of the inhibitor (Fig. 2). Steady-state data are given in Table 2 following addition of 0.1 and $0.2 \mu \mathrm{g} \mathrm{PEX} \mathrm{m}{ }^{-1}$, both of which significantly reduced the nitrite concentration. The lower concentration increased cell concentration and yield coefficient, as with stimulation of Nitrosomonas, but also reduced the rate of substrate oxidation per cell. At $0 \cdot 2 \mu \mathrm{g} \mathrm{PEX} \mathrm{ml} l^{-1}$, however, the only major change was a slight increase in cell concentration. The steady-state cell concentration was established earlier and with fewer oscillations following addition of the lower PEX concentration.

\section{Inhibition of ammonia and nitrite oxidation}

Addition of medium containing 2, 3 or $4 \mu \mathrm{g} \mathrm{PEX} \mathrm{ml} \mathrm{Pl}^{-1}$ to steady-state cultures of Nitrosomonas inhibited ammonia oxidation. Typical data are illustrated in Fig. 3 following addition of $4 \mu \mathrm{g}$ PEX ml $\mathrm{I}^{-1}$, which resulted in an increase in ammonium concentration to a new steady-state 


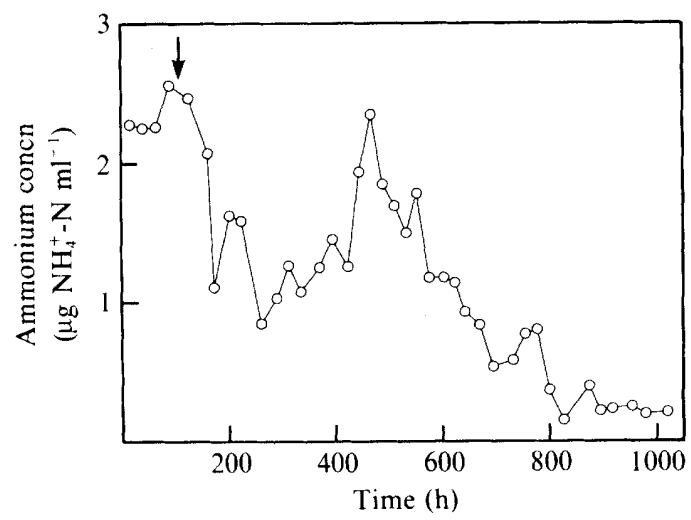

Fig. 1. Changes in ammonium concentration following addition of PEX $\left(0 \cdot 2 \mu \mathrm{g} \mathrm{ml}^{-1}\right)$ to a steady-state culture of Nitrosomonas. Ammonium concentrations were estimated at intervals of 1-2 h and data have been smoothed to improve presentation by plotting the mean of groups of eight successive data values. The time at which medium was supplemented with PEX is indicated by the arrow.

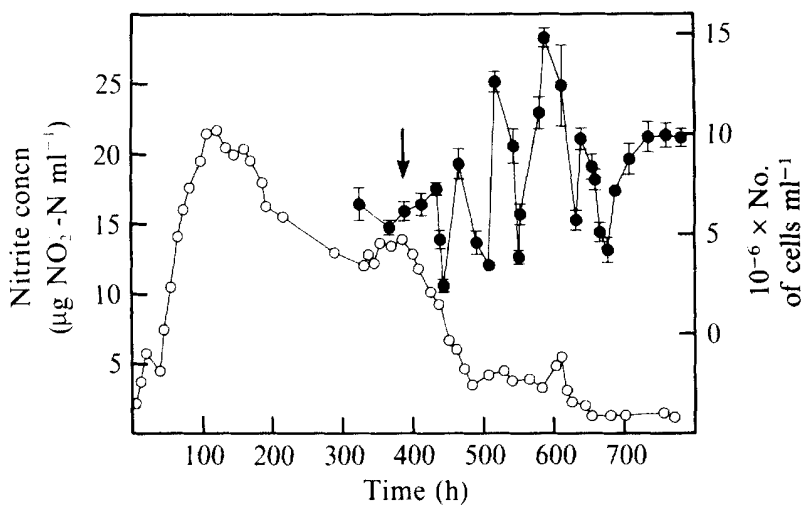

Fig. 2. Changes in nitrite concentration $(O)$ and cell concentration $(O)$ following addition of PEX $\left(0.2 \mu \mathrm{g} \mathrm{ml}^{-1}\right)$ to a steady-state culture of Nitrobacter. The time at which medium was supplemented with PEX is indicated by the arrow. Nitrite concentration data have been smoothed as described in Fig. 1 and error bars for cell concentrations indicate SE values.

Table 1. Steady-state data for Nitrosomonas grown at $30^{\circ} \mathrm{C}$ in ammonia-limited continuous culture $\left(D=0.033 h^{-1}\right)$ in the presence and absence of PEX

Steady-state data in the absence of PEX represent the mean values from four cultures.

\section{PEX concn} $\left(\mu \mathrm{g} \mathrm{ml}^{-1}\right)$

$0 \cdot 0$
$0 \cdot 2$
$2 \cdot 0$
$3 \cdot 0$
$4 \cdot 0$

Ammonium concn ( $\mu \mathrm{g} \mathrm{NH}_{4}^{+}-\mathrm{N} \mathrm{ml}^{-1}$ )

$$
\begin{gathered}
2 \cdot 37 \\
0 \cdot 37 \\
32 \cdot 8 \\
44 \cdot 0 \\
46 \cdot 9
\end{gathered}
$$

$10^{8} \times$ Rate of ammonia oxidation ( $\mu \mathrm{g} \mathrm{N}$ per cell $\mathrm{h}^{-1}$ )

8.0
8.5
10.9
5.8
2.7

Yield coefficient [ $\mu \mathrm{g}$ biomass $(\mu \mathrm{g} \mathrm{N})^{-1}$ ]

concentration after approximately $220 \mathrm{~h}$. Steady-state data are given in Table 1. Addition of all inhibitory PEX concentrations increased the steady-state ammonium concentration, reduced steady-state cell concentration, increased yield coefficient and, with the exception of $2 \mu \mathrm{g}$ PEX $\mathrm{ml}^{-1}$, decreased the ammonia oxidation rate per cell. A PEX concentration of $5 \mu \mathrm{g} \mathrm{ml}^{-1}$ resulted 


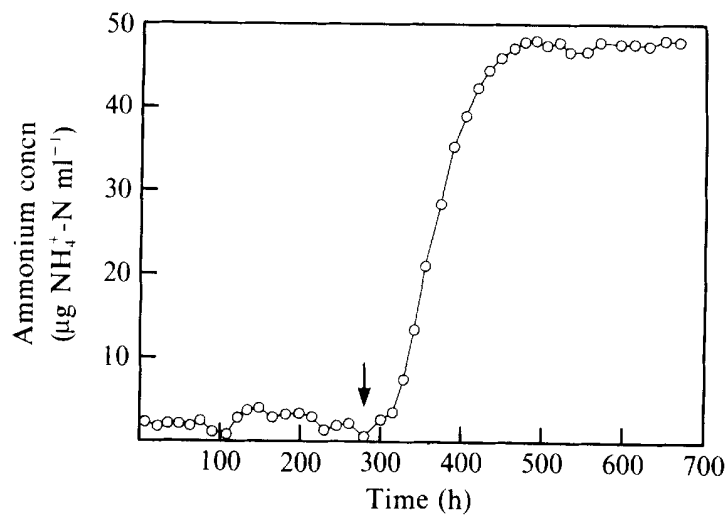

Fig. 3. Changes in ammonium concentration following addition of PEX ( $\left.4 \mu \mathrm{g} \mathrm{ml}^{-1}\right)$ to a steady-state culture of Nitrosomonas. The time at which medium was supplemented with PEX is indicated by the arrow. Ammonium concentrations were estimated at intervals of $1-2 \mathrm{~h}$ and data have been smoothed to improve presentation as described in Fig. 1.

Table 2. Steady-state data for Nitrobacter grown at $30^{\circ} \mathrm{C}$ in ammonia-limited continuous culture $\left(D=0.033 h^{-1}\right)$ in the presence and absence of PEX

Steady-state data in the absence of PEX represent the mean values from five cultures.

\begin{tabular}{|c|c|c|c|c|}
\hline $\begin{array}{l}\text { PEX concn } \\
\left(\mu \mathrm{gl} \mathrm{m}^{-1}\right)\end{array}$ & $\begin{array}{c}\text { Nitrite concn } \\
\left(\mu \mathrm{g} \mathrm{NO}_{2}^{-}-\mathrm{N} \mathrm{ml}^{-1}\right)\end{array}$ & $\begin{array}{l}10^{-7} \times \text { No. } \\
\text { of cells } \mathrm{ml}^{-1}\end{array}$ & $\begin{array}{c}10^{8} \times \text { Rate of } \\
\text { nitrite oxidation } \\
\left(\mu \mathrm{g} \mathrm{N} \text { per cell } \mathrm{h}^{-1}\right)\end{array}$ & $\begin{array}{c}\text { Yield coefficient } \\
{\left[\mu \mathrm{g} \text { biomass }(\mu \mathrm{g} \mathrm{N})^{-1}\right]}\end{array}$ \\
\hline 0.0 & 14.8 & 0.89 & 5.9 & 0.04 \\
\hline $0 \cdot 1$ & $10 \cdot 4$ & $2 \cdot 42$ & $2 \cdot 5$ & 0.04 \\
\hline 0.2 & $2 \cdot 4$ & 1.09 & $6 \cdot 5$ & 0.04 \\
\hline $6 \cdot 0$ & $25 \cdot 3$ & 0.34 & 10.9 & 0.07 \\
\hline $7 \cdot 0$ & $32 \cdot 1$ & 0.26 & $10 \cdot 3$ & 0.06 \\
\hline $9 \cdot 0$ & $37 \cdot 6$ & 0.11 & 16.8 & ND \\
\hline $10 \cdot 0$ & $43 \cdot 8$ & 0.22 & $4 \cdot 1$ & ND \\
\hline
\end{tabular}

in complete wash-out and must therefore have reduced the maxiumum specific growth rate below the dilution rate of $0.033 \mathrm{~h}^{-1}$.

Inhibition of nitrite oxidation was observed following the addition of $6,7,9$ and $10 \mu \mathrm{g}$ xanthate $\mathrm{ml}^{-1}$ to steady-state cultures of Nitrobacter. In each case a steady-state nitrite concentration was established after approximately $300 \mathrm{~h}$ and addition of PEX resulted in oscillations in cell concentration. These oscillations were most prolonged following addition of $10 \mu \mathrm{g} \mathrm{PEX} \mathrm{ml}^{-1}$ (Fig. 4), where a steady state was not established until approximately $600 \mathrm{~h}$ after addition of PEX, even though a steady state had been established in substrate concentration. Steady-state data are given in Table 2 and show similar behaviour to Nitrosomonas with respect to increase in substrate concentration and yield coefficient and decrease in cell concentration. The rate of substrate oxidation per cell, however, increased at 6,7 and $9 \mu \mathrm{g} \mathrm{PEX} \mathrm{ml} \mathrm{m}^{-1}$ but decreased at the highest concentration tested.

\section{Analysis of steady-state data}

Steady-state data at different concentrations of inhibitor may provide an insight into the mechanisms and kinetics of inhibition. Pirt (1976) distinguished between competitive and noncompetitive inhibition, using kinetics analogous to those for inhibition of enzyme reactions. Competitive inhibition increases the saturation constant for growth $\left(K_{\mathrm{s}}\right)$ but does not alter the maximum specific growth rate $\left(\mu_{\max }\right)$. Non-competitive inhibition reduces maximum specific 


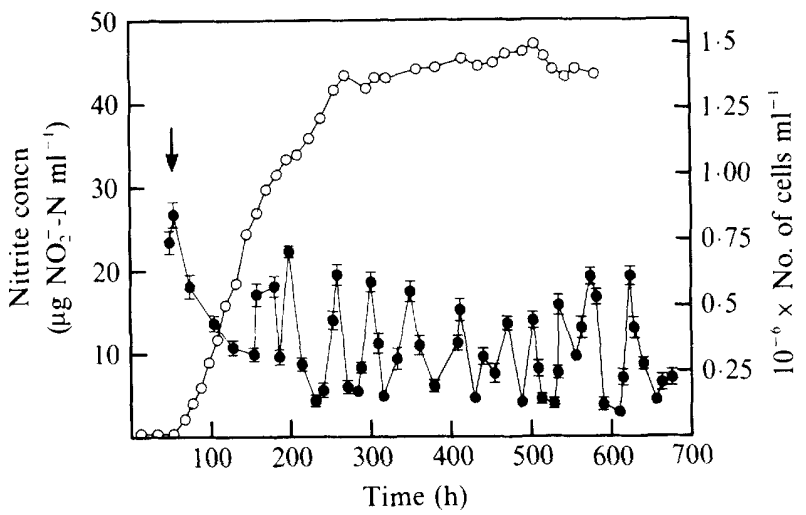

Fig. 4. Changes in nitrite concentration $(O)$ and cell concentration $(O)$ following addition of PEX $\left(10 \mu \mathrm{g} \mathrm{ml}^{-1}\right)$ to a steady-state culture of Nitrobacter. The time at which medium was supplemented with PEX is indicated by the arrow. Nitrite concentration data have been smoothed as described in Fig. 1 and error bars for cell concentrations indicate $\mathrm{SE}$ values.

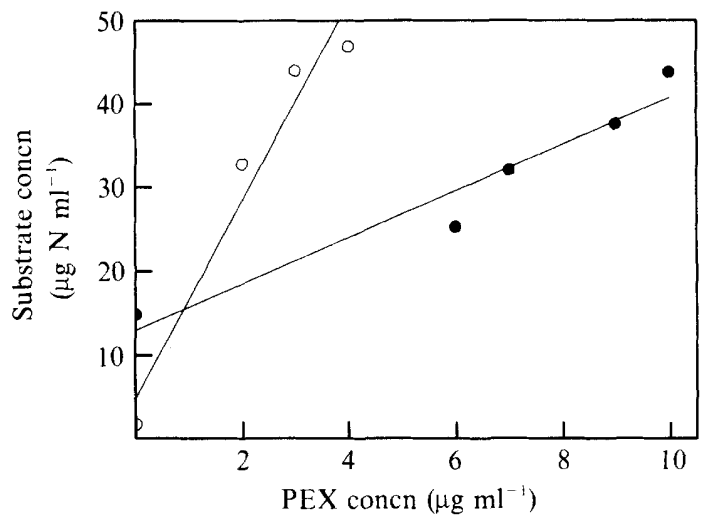

Fig. 5. Relationship between steady-state substrate concentration and concentration of PEX for Nitrosomonas $(O)$ and Nitrobacter $(O)$ in ammonia- and nitrite-limited continuous cultures. The lines plotted are the lines of best fit calculated by linear regression analysis.

growth rate but does not affect the saturation constant. The specific growth rate $(\mu)$ under the two forms of inhibition may be represented by the following equations.

Competitive inhibition

$$
\mu=\frac{\mu_{\max } s}{s+\alpha K_{\mathrm{s}}}
$$

Non-competitive inhibitor

$$
\mu=\frac{\mu_{\max } s}{\alpha\left(s+K_{\mathrm{s}}\right)}
$$

where $s=$ substrate concentration, $\alpha=1+i / K_{\mathrm{i}}, i=$ inhibitor concentration and $K_{\mathrm{i}}$ is the dissociation constant for inhibitor. Incorporation of these expressions into equations describing rates of change in substrate and biomass concentration in the chemostat lead to the following steady-state relationships for competitive and non-competitive inhibition.

Competitive inhibition

$$
\bar{s}=c+c i / K_{\mathrm{i}}
$$


Non-competitive inhibition

$$
i=\frac{\mu_{\max } K_{\mathrm{i}}}{D_{\text {crit }}}-K_{\mathrm{i}}
$$

where $\bar{s}=$ steady-state substrate concentration, $c=D K_{\mathrm{s}} /\left(\mu_{\max }-D\right)$ and $D_{\text {crit }}$ is the critical dilution rate. A linear plot of $\bar{s}$ against $i$ indicates competitive inhibition and $K_{\mathrm{i}}$ may be calculated from the slope and intercept. For non-competitive inhibition a plot of $i$ against $1 / D_{\text {crit }}$ is linear and $\mu_{\max }$ and $K_{\mathrm{i}}$ may be calculated from the slope and intercept. Estimation of the critical dilution rate for nitrifying bacteria was not feasible, because of their low specific growth rates, and the consequent length of time required to determine accurately the $D_{\text {crit. }}$. Fig. 5 is a plot of $\bar{s}$ against $i$ for both Nitrosomonas and Nitrobacter with lines of best fit calculated by linear regression. Analysis of variance of data for Nitrosomonas yields an $F$-value of $35 \cdot 0$, giving a probability of 0.027 with one and two degrees of freedom. For Nitrobacter, the $F$-value is 44.6 , giving a probability of 0.0068 with one and three degrees of freedom. At the $5 \%$ level of significance, therefore, both sets of data have significant linearity but with more variability in those for Nitrosomonas. It was not feasible to determine more steady-state data and conclusions drawn from those for Nitrosomonas must be treated with some caution. Assuming linearity, and therefore competitive inhibition, values for $K_{\mathrm{i}}$ of $0.41 \mu \mathrm{g} \mathrm{PEX} \mathrm{ml}^{-1}$ and $4.7 \mu \mathrm{g} \mathrm{PEX} \mathrm{ml} l^{-1}$ are obtained.

\section{Ammonia and nitrite oxidation in batch culture}

Experiments were done to determine whether inhibitory and stimulatory effects could be observed on exponentially growing cells in batch culture and to look for long-term adaptation to growth in continuous culture in the presence of PEX. Specific growth rates were determined before and after addition of PEX to exponentially growing cultures of Nitrosomonas and Nitrobacter. No evidence of stimulation or inhibition was found for Nitrosomonas at $0 \cdot 1 \mu \mathrm{g}$ PEX $\mathrm{ml}^{-1}$ but a concentration of $0.8 \mu \mathrm{g} \mathrm{PEX} \mathrm{ml}{ }^{-1}$ significantly reduced specific growth rate from $0.043 \mathrm{~h}^{-1}$ to $0.023 \mathrm{~h}^{-1}$. The specific growth rate of Nitrobacter was significantly increased from $0.036 \mathrm{~h}^{-1}$ to $0.039 \mathrm{~h}^{-1}$ ( $5 \%$ level of significance) following addition of $0.1 \mu \mathrm{g} \mathrm{PEX} \mathrm{ml}^{-1}$, which also stimulated nitrite oxidation in continuous culture. However, $0.2 \mu \mathrm{g} \mathrm{PEX} \mathrm{ml} \mathrm{m}^{-1}$, which stimulated nitrite oxidation in continuous culture, did not affect specific growth rate in batch culture and addition of $0.8 \mu \mathrm{g}$ PEX ml ${ }^{-1}$ significantly reduced specific growth rate from $0.036 \mathrm{~h}^{-1}$ to $0.028 \mathrm{~h}^{-1}$.

The long-term effect of exposure of Nitrosomonas to PEX was investigated by sampling cells exposed to $1.0 \mu \mathrm{g} \mathrm{PEX} \mathrm{ml}^{-1}$ for $1280 \mathrm{~h}$ in continuous culture. The cells were then grown in batch

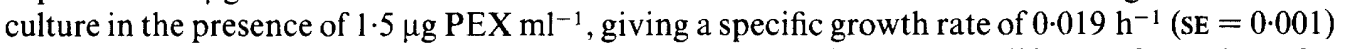
and a lag phase of $63 \mathrm{~h}(\mathrm{SE}=6 \cdot 65)$. These values are not significantly different from those for cells cultured in the absence of PEX (Underhill \& Prosser, 1985) and grown in batch culture with $1.5 \mu \mathrm{g} \mathrm{PEX} \mathrm{m} l^{-1}$. Nitrobacter cells were removed from a chemostat after $1000 \mathrm{~h}$ exposure to $1.0 \mu \mathrm{g} \mathrm{PEX} \mathrm{ml}^{-1}$ and were then grown in batch culture in the absence of PEX. A specific growth of $0.059 \mathrm{~h}^{-1}(\mathrm{SE}=0.008)$ was observed, which was not significantly different from that of cells routinely cultured in the absence of PEX and then grown in the presence of $1.0 \mu \mathrm{g} \mathrm{PEX} \mathrm{ml} \mathrm{P}^{-1}$ $\left(0.056 \mathrm{~h}^{-1}, \mathrm{SE}=0.002\right)$. The lag phase was not significantly different and there is therefore no evidence for adaptation of either Nitrosomonas or Nitrobacter on prolonged exposure to PEX.

\section{DISCUSSION}

Underhill \& Prosser (1985) studied the inhibition of pure cultures of Nitrosomonas and Nitrobacter by PEX in liquid batch culture and in soil. In both experimental systems, increasing PEX concentrations decreased the maximum specific growth rate and increased the lag phase before ammonia and nitrite oxidation, although there was some evidence of stimulation of Nitrobacter by a concentration of $0.8 \mu \mathrm{g} \mathrm{ml}^{-1}$. While such batch systems are typically used to test the efficacy of inhibitors of nitrification and other processes, they cannot assess the influence of two factors which are significant in many natural environments. The first is substrate limitation 
and the second is the effect of inhibitors on growing, rather than stationary-phase, cells. In this study we have demonstrated significant stimulation of ammonia and nitrite oxidation by continuous cultures of Nitrosomonas and Nitrobacter at concentrations of PEX which had no effect on growth in batch culture. This has important implications for the application of such inhibitors to agricultural soils. Diffusion of inhibitor away from regions of direct application will provide areas of low concentration where nitrification, and hence nitrogen losses, would be increased, rather than decreased. Addition of low concentrations of PEX to exponentially growing cells in batch culture produced only slight stimulation of Nitrobacter and did not stimulate growth of Nitrosomonas. This suggests that stimulation is a feature of substrate-limited cells and does not significantly effect the maximum specific growth rate. The relationship between substrate concentration and inhibitor concentration must therefore be considered when using inhibitors to reduce losses of ammonium-based fertilizers through nitrification.

Concentrations of PEX which inhibited growth of Nitrosomonas and Nitrobacter in batch culture also inhibited ammonia and nitrite oxidation in continuous culture. In batch culture PEX concentrations of $1 \mu \mathrm{g} \mathrm{ml}$ m $^{-1}$ and above $0.2 \mu \mathrm{g} \mathrm{ml}^{-1}$ induced long lag phases for Nitrosomonas and Nitrobacter, respectively. For example, a concentration of $3 \mu \mathrm{g} \mathrm{PEX} \mathrm{ml} \mathrm{m}^{-1}$ induced a lag period of $502 \mathrm{~h}$ for Nitrosomonas and concentrations above $1 \mu \mathrm{g} \mathrm{ml}^{-1}$ prevented growth of Nitrobacter within 7 weeks. Lag phases of this length would have led to complete wash-out in the continuous culture experiments described here. In fact stable steady-states were observed within 160-180 h and 120-240 h for Nitrosomonas and Nitrobacter respectively. Inhibition of actively growing, substrate-limited cells is therefore different to that of stationaryphase cells, possibly affecting maximum specific growth rate, and other growth parameters, but not inducing a significant lag phase.

Steady-state data for both organisms show that stimulation is associated with an increase in cell concentration and, in some cases, an increase in yield coefficient. The rate of substrate conversion per cell, however, changed little. Stimulation of growth of nitrifying bacteria by a range of organic compounds has been reported (see Bock et al., 1986). Continuous culture allows assessment of effects on activity and steady-state data indicate uncoupling of biomass synthesis and substrate oxidation. Inhibitory concentrations of PEX affected steady-state data for Nitrosomonas and Nitrobacter differently. Inhibition of Nitrosomonas was associated with a decrease in cell concentration and activity and an increase in yield coefficient. PEX therefore reduced the rate at which a cell oxidized ammonia but increased the efficiency with which the cell could convert energy generated into biomass. There have been no reports of heterotrophic or mixotrophic growth of Nitrosomonas and the cultures were not carbon-limited. The data imply an increase in cell mass, possibly associated with increased production of extracellular capsular material. Inhibition of Nitrobacter was also associated with a decrease in concentration and yield

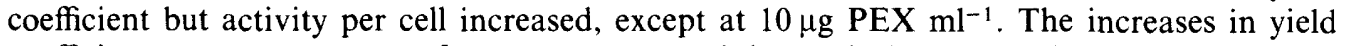
coefficient were not as great as for Nitrosomonas and the results indicate an increase in substrate utilization for maintenance at inhibitory concentrations. The increase in yield may be due to assimilation of organic carbon, which has been reported elsewhere for Nitrobacter (see Bock et al., 1986).

Plots of steady-state substrate concentration against inhibitor concentration indicate competitive inhibition for Nitrobacter and possibly for Nitrosomonas, although lack of data for the latter necessitate caution in drawing conclusions. The biochemical mechanism for inhibition by PEX has not been elucidated. Anderson et al. (1968) found inhibition by ethyl xanthate of a peroxidase of Nitrosomonas, but could not demonstrate a physiological role for this enzyme in ammonia oxidation. Erickson \& Hooper (1968) demonstrated inhibition by ethyl xanthate of a soluble oxidase from Nitrosomonas while Lees (1952) classified xanthates, with other inhibitors, as chelating agents of metal components of enzymes involved in ammonia oxidation. Chelating agents would be expected to act as non-competitive inhibitors but there is no evidence of noncompetitive inhibition from our data.

The effect of PEX on transient growth was monitored by following changes in substrate concentration and, for Nitrobacter, changes in cell concentration. Addition of inhibitory concentrations of PEX resulted in monotonic decreases in substrate concentration to new 
steady-state concentrations. Stimulatory concentrations of PEX were associated with more variable behaviour as PEX concentration within the vessel increased and, in the case of Nitrosomonas, the time required for establishment of new steady states was greatly increased. Addition of both stimulatory and inhibitory concentrations of PEX produced oscillations in Nitrobacter cell populations. These became damped as steady states in nitrite concentration were established but at a concentration of $10 \mu \mathrm{g} \mathrm{PEX} \mathrm{ml}^{-1}$ they continued long after establishment of a steady state. The period of oscillation was approximately $45-50 \mathrm{~h}$. At a dilution rate of $0.05 \mathrm{~h}^{-1}$, the doubling time of the culture is $46 \mathrm{~h}$, suggesting that addition of PEX induced synchronous division. Although this may have occurred, it would be more likely if the new PEX concentration was reached immediately and not gradually.

S.E.U. acknowledges receipt of a SERC research studentship.

\section{REFERENCES}

Anderson, J. R., Strumeyer, D. H. \& Pramer, D. (1968). Purification and properties of peroxidase from Nitrosomonas europaea. Journal of Bacteriology 96, 93-97.

Ashworth, J., Briggs, G. G., Evans, A. \& Matula, J. (1977). Inhibition of nitrification by nitrapyrin, carbon disulphide and trithiocarbonate. Journal of the Science of Food and Agriculture 28, 673-683.

Ashworth, J., Rodgers, G. A. \& Briggs, G. G. (1979). Xanthates as inhibitors of fertilizer nitrogen transformation in soil. Chemistry and Industry 3, 90-92.

Ashworth, J., Penny, A., Widdowson, F. V. \& Briggs, G. G. (1980). The effects of injecting nitrapyrin ("N-Serve"), carbon disulphide or trithiocarbonates, with aqueous ammonia on yield and \% $\mathrm{N}$ of grass. Journal of the Science of Food and Agriculture 31, 229-237.

Bock, E. (1965). Vergleichende Untersuchungen über die Wirkung sichtbaren Lichtes auf Nitrosomonas europaea und Nitrobacter winogradskyi. Archiv für Mikrobiologie 51, 18-41.

Bock, E., Koops, H.-P. \& Harms, H. (1986). Cell biology of nitrifying bacteria. In Nitrification, Special Publication of the Society for General Microbiology, vol. 20, pp. 17-38. Edited by J. I. Prosser. Oxford: IRL Press.

Erickson, R. H. \& HoOPER, A. B. (1968). A soluble hydroquinone oxidase from Nitrosomonas europaea. Bacteriological Proceedings, 140.

Glover, H. E. (1985). The relationship between inorganic nitrogen oxidation and organic carbon production in batch and chemostat cultures of marine nitrifying bacteria. Archives of Microbiology 142, $45-50$.
GoRING, C. A. I. (1962). Control of nitrification of ammonium fertilizers and urea by 2-chloro-6-(trichoromethyl)pyridine. Soil Science 93, 431-439.

KeEN, G. A. \& Prosser, J. I. (1987a). Steady state and transient growth of autotrophic nitrifying bacteria. Archives of Microbiology 147, 73-79.

KeEn, G. A. \& Prosser, J. I. (1987b). The surface growth and activity of Nitrobacter. Microbial Ecology (in the Press).

LEES, H. (1952). The biochemistry of nitrifying organisms. I. The ammonia-oxidising systems of Nitrosomonas. Biochemical Journal 52, 134-139.

PIRT, S. J. (1976). Principles of Microbe and Cell Cultivation. Oxford: Blackwell Scientific Publications.

Powlson, D. S. \& Jenkinson, D. S. (1971). Inhibition of nitrification in soil by carbon disulphide from rubber bungs. Soil Biology and Biochemistry 3, 267269.

Prosser, J. I. \& BazIN, M. J. (1987). The use of packed column reactors to study microbial nitrogen transformations in the soil. In $A$ Handbook of Laboratory Systems for Microbial Ecosystems Research. Edited by J. W. T. Wimpenny. CRC Press (in the Press).

SkINNER, F. A. \& WALKeR, N. (1961). Growth of Nitrosomonas europaea in batch and continuous culture. Archiv für Mikrobiologie 39, 339-349.

UNDERHILl, S. E. \& Prosser, J. I. (1985). Inhibition of nitrification by potassium ethyl xanthate in soil and in liquid culture. Soil Biology and Biochemistry 17, 229-233.

Underhill, S. E. \& Prosser, J. I. (1987). The attachment of nitrifying bacteria and inhibition by potassium ethyl xanthate. Microbial Ecology (in the Press). 